\title{
The Bioethics of Human Pluripotent Stem Cells: Will Induced Pluripotent Stem Cells End the Debate?
}

\author{
Julia C. Watt ${ }^{1}$ and Nao R. Kobayashi*, ${ }^{*}$ \\ ${ }^{I}$ Department of Philosophy, University of Western Ontario, London, Ontario, Canada \\ ${ }^{2}$ O'Brien Institute and University of Melbourne, Melbourne, Victoria, Australia
}

\begin{abstract}
The ethical debate surrounding human pluripotent stem (PS) cell research is mainly due to use of human embryonic stem (ES) cells. It has been suggested by many that human induced pluripotent stem (iPS) cells would end the debate due to their non-embryonic origin. This review examines the ethical issues surrounding the use of iPS cells and their ES cell counterparts, and argues that while iPS cells are in many ways ethically less contentious, they will certainly not end the debate.
\end{abstract}

Keywords: Embryonic stem cells, induced pluripotent stem cells, somatic cell nuclear transfer, germ line, ethics, moral status, beneficence.

\section{INTRODUCTION}

The ethical controversy surrounding human PS cell research is largely due to the use of ES cells that have been obtained from human embryos. The promise of nonembryonic human iPS cells is therefore viewed by many as a panacea to the ethical woes that have plagued human PS cell research to date $[1,2]$.

To avoid creating false hope in the minds of researchers, policy makers and the general public, it is essential that the potential of iPS cell technology to provide an ethically less problematic alternative to ES cells be carefully examined early on. Following Takahashi and Yamanka's ground breaking discovery in 2006 [3], which described the induction of pluripotency in murine somatic cells, understanding the ethical implications of iPS cell technology has been advanced by only a few papers [4-8]. This review aims to build on these earlier efforts by integrating the ethical considerations they raise into a cohesive account of 1) the ethical problems arising from research using human ES cells, 2) the extent to which human iPS cells will solve these problems and 3) potential new ethical problems created by the use of human iPS cells.

\section{ETHICAL PROBLEMS CREATED BY THE USE OF HUMAN ES CELLS}

All research involving human subjects is guided by three fundamental ethical principles: respect for persons, beneficence and justice. These principles give rise to such familiar obligations as the duty to obtain informed consent from subjects prior to enrolment in research, the duty to

*Address correspondence to this author at the O'Brien Institute, 42 Fitzroy Street, Melbourne, Victoria, 3065 Australia; Tel: +61 3 9288-4030; Fax: +61 3 9416-0926; E-mail: naok@unimelb.edu.au ensure that participation offers a favorable balance of risks versus benefits and the duty to ensure that these risks and benefits are distributed in an equitable fashion. Insofar as stem cell research requires the participation of adults or children as tissue donors or recipients, it places the same ethical responsibilities on researchers as any other research program conducted using human subjects. Thus, for example, informed consent must be obtained from prospective donors of embryos, gametes or somatic cells and from prospective recipients of experimental stem cell therapies.

However, with respect to human ES cell research, applying the principles of respect for persons, beneficence and justice is complicated by the use of human embryos for research purposes, which raises difficult questions about the moral status of embryos and researchers' ethical obligations toward them. The resulting "stem cell debate" has been predominately focused on the treatment of embryos as research subjects and been driven by concerns about harm to embryos (arising from the principle of beneficence) and respect for human life (arising from the principle of respect for persons). Although to a lesser extent, there have also been concerns raised about the potential exploitation of women for their ova (best understood as arising from the principle of justice). In addition to the above concerns specifically related to the treatment of research subjects, there have been much broader concerns raised about the potentially deleterious social consequences of permitting human PS cell research due to the commodification of human life.

\section{Harm to Embryos and Respect for Human Life}

Respect for persons entails a moral duty to recognize human beings as having interests of their own that must be respected and to never treat human beings as mere means. This typically requires that researchers respect individual autonomy (i.e., respect individuals' ability to deliberate and 
make choices on the basis of their own interests) by obtaining the informed consent of subjects prior to their enrolment in a research protocol. However, when autonomy is absent or impaired, respect for persons requires more direct measures to protect individuals' fundamental human interest in avoiding harm. Thus, when dealing with vulnerable persons or groups the principle of respect for persons can merge with the principle of beneficence, which states that research must not be conducted in a manner that is harmful to human subjects.

Although the principle of beneficence appears straightforward, its application often requires complex risk-tobenefit calculations since it does not mean that human subjects cannot be exposed to any risk of harm in the course of research, just that research cannot be harmful to subjects on balance. Thus, it is permissible to expose consenting subjects to some degree of risk provided the potential for harm is unavoidable and the risk is balanced by the potential benefits. However, as previously discussed, the principle of respect for persons requires special protections for subjects who are unable to consent to being exposed to such risks, and may even require excluding them from participating in potentially harmful research altogether, as established by the Common Rule (45 CFR 46.111(b)) [9].

For those who consider embryos to be persons, and thus owed full moral consideration in their own right, the destruction of embryos to harvest their stem cells is obviously a gross violation of the principles of respect for persons and beneficence. Indeed, if embryos are persons then virtually no form of experimentation on embryos bearing greater than minimal risk would be permissible (experimental treatments aimed at protecting an embryo from other more serious harms being the only possible exception [10]). Less obviously, the destruction of human embryos for research purposes also raises concerns for those who deny that embryos are persons due to their potential to develop into persons. To show complete moral disregard for what is at least a potential person would reflect an inappropriate disregard for the value of human life, and so for the lives of persons; thus, respect for persons entails a measure of respect for human life and its potential. Hence, even among those who deny that human embryos are owed the same ethical consideration as persons, there is a general consensus that embryos are owed some special consideration and that their destruction is therefore not morally neutral. While the destruction of embryos may be justifiable in light of the potential benefits of human ES cell research, their destructtion is deeply regrettable and this practice remains justified only insofar as there exists no alternative means of obtaining the benefits in question [11].

The existence of widespread concern about the destructtion of embryos has encouraged the development of alternative means of obtaining human ES cells in an effort to avoid the destruction of viable embryos. Proposed alternatives include deriving human ES cells from somatic cells via somatic cell nuclear transfer (SCNT), harvesting them from non-viable embryos via altered nuclear transfer (ANT) or harvesting them via blastocyst biopsy. However, as explained below, these alternative derivation techniques not only face a variety of technical hurdles, but also offer little hope of resolving any of the ethical concerns.

\section{Deriving Human ES Cells Using SCNT}

SCNT involves inserting the nucleus of a somatic cell into an enucleated, unfertilized oocyte and stimulating the oocyte to develop into an embryo. Once the embryo has reached the blastocyst stage, the inner cell mass can be harvested and used to derive an ES cell line (this use of SCNT is termed "therapeutic cloning"). This method of deriving ES cells has been carried out in several mammalian species $[12,13]$, and been shown to produce cells that display typical pluripotent markers (e.g., Oct3/4, nanog and SSEA1) and that are transcriptionally and functionally indistinguishable from conventionally derived ES cells [14-16]. Although, to date, no human ES cell lines have been established using SCNT, blastocysts have been successfully obtained from cloned human embryos suggesting that SCNT could potentially be used to establish human ES cell lines [17].

However, human ES cell lines established using SCNT would be no less controversial than those established by more conventional means. A cloned human embryo is still a human embryo; hence, its destruction would be just as problematic as the destruction of embryos obtained more conventionally from in vitro fertilization (IVF). In fact, in many ways therapeutic human cloning would actually be more controversial than other approaches to obtaining human ES cells (including IVF, ANT and blastomere biopsy). For example, SCNT's low success rate in animal studies [18] suggests that large numbers of human embryos might have to be created in order to obtain a single viable blastocyst for cell line isolation. Thus, deriving human ES cells using SCNT might require the destruction of many more embryos than other methods. Another reason for concern over deriving human ES cells using SCNT is that therapeutic human cloning could lead to reproductive human cloning. The potential for SCNT technology to be used for reproductive purposes is seen by many as a slippery slope leading to a host of moral and social dangers. While some of the dangers that have been associated with reproductive cloning arise from erroneous beliefs in genetic determinism (e.g., fears of an army of Hitler or the loss of individuality [19]), there are also more plausible worries about the welfare of clones and the implications for "the family" and human society (e.g., fears about the creation of clones to use as spare parts, parents cloning "replacements" for deceased children or the creation of human-animal hybrids [20]).

\section{Deriving Human ES Cells Using ANT}

As explained above, human ES cell derivation using SCNT would not avert harm to embryos and the associated ethical dilemmas. To avoid ending any actual or potential human lives it has been suggested that, prior to nuclear transfer, the nucleus of the somatic donor cell or cytoplasm of the enucleated oocyte should be altered such that the reconstituted cell will be unable to develop past the blastocyst stage, making it suitable for deriving ES cells but not viable as an embryo [21]. This approach has considerable practical merit since it has been established that non-viable embryos suitable for ES cell derivation can be produced via RNA interference-mediated silencing of the Cdx2 gene in the nuclear donor cell prior to nuclear transfer [22]. Because $\mathrm{Cdx} 2$ is required for the proper development of extra- 
embryonic structures such as placental and amniotic tissues Cdx2-knockout blastocysts fail to survive implantation, but the inner cell mass of Cdx2-knockout blastocysts can be used to produce ES cells.

Despite the potential of ANT, the possibility of engineering non-viable human embryos in this fashion also does little to lessen the controversial nature of human ES cell research. Those who take a hard line on the moral status of embryos have repudiated ANT as amounting to scientists engineering disabled human beings for experimental purposes. ANT is also problematic for those with more moderate views on the moral status of embryos, since intentionally creating a nonviable human embryo would entail depriving that embryo of the potential it could have had to develop to term (being nonviable the embryo itself never possessed the potential to develop, but it would have possessed it were it not for the silencing of the Cdx2 gene) [4]. Admittedly, since an ANT embryo is nonviable one cannot claim that it is directly deprived of its potential to develop as one can with SCNT embryos (the Cdx2 gene being silenced prior to the creation of the embryo); thus, one could argue that there is no victim and, hence, no harm. However, since the act in question is done specifically in order to deprive a particular (albeit yet-to-be-created) embryo of any potential for life, it could just as well be argued that there is a particular victim of the harm even though the harm is done prior to that victim's existence. Furthermore, any use of embryos created for research purposes (viable or not) is more controversial than the use of embryos that were originally created for reproductive purposes, since the latter is seen by many as respecting the special moral status of human embryos in a way that their creation for research does not [23].

An obvious way for researchers to attenuate their moral responsibility for harming embryos would be to restrict research to naturally occurring non-viable embryos. Such a practice would be somewhat less problematic than ANT, in that researchers would not be responsible for depriving embryos (or embryos-to-be) of any developmental potential, and is thus less obviously a problem for the principles of respect for persons and beneficence. Yet, even using naturally occurring non-viable human embryos would not end the moral controversy surrounding the harvest of human ES cells. For those who consider human embryos to be persons, destroying such embryos would amount to killing disabled (or terminally ill) people, something that is just as immoral as killing non-disabled or healthy people. For those who consider embryos to be only potential persons, destroying these embryos would still amount to destroying what could have been a potential person and interposing this additional layer of potentiality merely renders their connection to persons more remote, it does not sever the connection and so does not eliminate the ethical concerns (as was discussed above). Moreover, restricting research to naturally occurring non-viable embryos would create significant technical difficulties since it would negatively effect the quality of the embryos that were available for human ES cell derivation purposes, since naturally occurring cases of non-viability are likely to often be the product of genetic dysfunction which would make the derivation of functional human ES cells impossible [24].

\section{Deriving Human ES Cells Using Blastocyst Biopsy}

Harvesting ES cells via blastocyst biopsy has been suggested as a way to avoid the destruction of embryos altogether. Blastocyst biopsy is an ethically accepted procedure that is already standard practice in the context of IVF, in which a single blastomere is removed from the blastocyst prior to implantation to perform genetic screening. It has been shown that ES cell lines can be derived from a single blastomere; for example, blastomere-derived mouse ES cell lines show all the characteristics of ES cells including pluripotent markers, long-term passage, teratoma formation, and germ line transmission [25]. Human ES cell lines established in this manner also appear to be feasible [26]; hence, it should be possible to take a single cell harvested from a blastocyst for pre-implantation genetic screening, culture this blastomere in vitro for a single round of mitosis, and then use one daughter cell for genetic screening while the other is used to derive a human ES cell line. However, to derive ES cells from a blastomere involves stimulating it to develop into a blastocyst (from which ES cells can then be derived in the same manner as in SCNT or ANT). There is evidence to suggest that human blastocysts created in this manner are unlikely to be viable embryos (since those created from fewer than two blastomeres of other mammalian species appear to be non-viable [27]), but insofar as this method of deriving ES cells would involve creating non-viable embryos it does not represent any ethical improvement on ANT (if the resultant blastocyst were in fact viable then this process would be more controversial since it would be ethically equivalent to SCNT).

\section{Exploitation of Women and Commodification of Human Life}

In addition to ethical problems arising from the principles of beneficence and respect for persons, some commentators have also raised concerns about the possible exploitation of women. Human ova are necessary for creating ES cells (whether via IVF or SCNT/ANT), and the demand for ES cell lines is likely to exceed the supply of "surplus" ova harvested and embryos created in the course of assisted reproduction. This will potentially lead to ova being harvested specifically for creating embryos for research. However, since the procedures involved in harvesting ova are risky, highly invasive and involve considerable discomfort, women are unlikely to consent to them purely for the sake of research. As such, there is the potential for the exploitation of disadvantaged women in countries that fail to adequately regulate or police the sale of human ova [5].

The potential market for human ova also raises more fundamental concerns about the commodification of human life. It has been argued that the instrumental use of human gametes, embryos, somatic cells or other human parts in stem cell research (let alone possible financial compensation to donors) and associated patenting of genes and cell lines promotes the idea of human life as a tradable commodity. Concerns about commodification arise from the idea that human life has intrinsic value - that is, has value in and of itself, as opposed to having merely instrumental value as a means to an end. Insofar as one values something primarily as a means to an end one treats it like a commodity - that is, 
like something whose value is determined by its instrumental value to others and is therefore reducible to the amount others are willing to pay for it. To commodify something that has intrinsic value by conceiving it in instrumental terms or, worse still, to actually put a price on it, thereby degrades it. Hence, it is argued, anything that causes or encourages people to think of human life, in any part or form, in terms of its instrumental use or purpose degrades the value of human life [28].

Insofar as human PS cell research uses, and creates a demand for, human embryos, gametes and somatic cells it encourages people to think of these parts (and hence of human life, which they embody) in terms of their value to research. This commodification of human life is morally wrong in itself since it degrades all human beings (by degrading human life generally) and it is also morally dangerous since it risks sending society down a slippery slope toward accepting more egregious forms of commodification, such as the genetic engineering of "designer babies", creating clones to harvest their organs or even human slavery.

\section{WILL IPS CELLS SOLVE THE PROBLEMS CREATED BY THE USE OF HUMAN ES CELLS?}

The rapidly advancing field of iPS cell technology (see reviews in this issue $[29,30]$ ) has been heralded by many as the definitive solution to the ethical problems that have faced human PS cell research. As discussed above, these problems are primarily the result of the fact that research has required harvesting stem cells from human embryos. Since iPS cells are derived directly from somatic cells by inducing stemness one might think that it would circumvent the problems faced by research using human ES cells since no embryos are harmed, no women are exploited for their ova and neither embryos nor gametes are commodified. However, the characteristics of iPS cells that make them potential substitutes for ES cells also raises some questions related to their developmental potential.

\section{Impact of Human iPS Cells on Harm to Embryos and Respect for Human Life}

Viable embryos can be obtained from iPS cells using tetraploid complementation in the same way they can be obtained from ES cells [31-33]. This means that human iPS cells could potentially be used for reproductive cloning and so are entangled in this aspect of the stem cell debate. Hence, the slippery slope arguments raised in opposition to SCNT, on the basis of its potential use for reproductive cloning, would also apply to iPS cells, although public fears would likely be mitigated by the fact that creating human iPS cells does not require the creation of actual clone embryos which could be implanted (as SCNT does), thereby making it one step further removed from reproductive cloning.

It must be pointed out that the potential for reproductive cloning is a relatively minor issue in comparison to harm to embryos, and the real promise of human iPS cells is that they would allow researchers to avoid this more controversial issue since they are not derived from embryos. However, despite the non-embryonic origins of iPS cells, it has been argued that the matter of harm to embryos cannot be entirely avoided, since PS cells possess problematic developmental capacities that blur the ethical lines between individual PS cells and embryos. ES cells in culture have been found to form embryoid bodies (EBs) capable of spontaneous (or, self-) organization and differentiation in ways that mirror processes observed in embryogenesis, including primitive streak formation and anterior-posterior axis formation [34]. Because human iPS cells appear to possess the same capacities as human ES cells (indeed, this is the goal in creating human iPS cells), they are thought to possess the same embryo-like developmental capacity. In embryology the differentiation of endoderm and mesoderm in the primitive streak and the formation of the main body axes are the hallmarks of individuation in which the basic body plan is established. In human embryology this process of early pattern formation is of ethical significance in the sense that it marks the point at which there exists a particular individual or entity to whom moral duties could potentially be owed (this is not to say that there exists a "person" in any moral sense). Insofar as EBs formed by PS cells, including ES and iPS cells, have the capacity to reach this stage of individuation it is argued that they are functionally analogous to embryos at a similar stage of development and, hence, should seen as having the same moral status [7].

In order to overcome the problem created by the developmental potential of human iPS cells it has been argued that researchers ought to have as their goal the creation of cells that lack developmental potential; in other words, that ES cell function should not be used as the gold standard against which iPS cell function is compared. This proposed solution might initially appear vulnerable to the objections raised against the generation of non-viable embryos: if iPS cells are analogous to embryos, then would rendering them unable to develop not be analogous to rendering embryos non-viable? However, the analogy does not hold in this case since the somatic cells that iPS cells are derived from are not analogous to embryos since somatic cells do not possess any inherent developmental potential that they could be deprived of. As such, it is argued that human iPS cell technology could produce a more ethical source of human PS cells provided the desirable properties of ES cells can be reproduced in a manner that does not reproduce their pattern forming potential.

If the above argument is correct it has significant implications for assessing the function of human iPS cells since it would prevent the use of EB formation for determining pluripotency. However, the assertion that a similar capacity for pattern formation entails that iPS cells are ethically analogous to embryos is at best questionable. As previously discussed, the general consensus that exists concerning embryos' special moral status is in virtue of their having the potential to develop into adult human beings, not in virtue of their capacity to achieve any particular early stage of embryonic development. The reason primitive streak and body axes formation is regarded as ethically relevant in human embryology is that this marks the point at which we can individuate particular potential human beings. It follows that no ethical relevance would attach to these processes when they occur in EBs insofar as these bodies do not have any such potential (the ethically controversial nature of human ES cells being due to the fact that they are derived 
from embryos which did have this potential). To claim that human iPS cells are ethically analogous to embryos entails denying the above claim and asserting that human iPS cells actually possess the potential to develop into human beings (i.e., that tetraploid complementation in iPS cells should be considered a form of self-organization).

The ethical question about the moral status of human iPS cells thus hinges on whether the process of tetraploid complementation is best understood as having internal or external causation-that is, as driven by the iPS cells themselves or by something external to them. If tetraploid complementation is understood as internally driven then it is something that will naturally occur unless prevented by external factors or events, such as the absence of tetraploidized helper cells (analogous to an embryo developing unless prevented from doing so). In contrast, if tetraploid complementation is understood as externally driven then it is something the iPS cells are caused to undergo by the introduction of tetraploidized helper cells in the same way that somatic cells are induced to become pluripotent by the introduction of reprogramming factors.

The question of causation is important because if iPS cells possess the potential to undergo tetraploid complementtation in the same way that embryos possess the potential to develop into adults (i.e., as something internally driven), then there is no basis for drawing an ethical distinction between the use of human iPS cells and the use of human embryos. Insofar as embryos' innate potential to develop into adult human beings gives them special moral status it is hard to see what justification could be given for withholding this status from human iPS cells if these cells possess an innate potential to develop into viable embryos and, hence, an innate potential to develop into adult human beings. However, there are reasons to think that the process of tetraploid complementation is better understood as something that iPS cells are made to undergo (i.e., something that is done to iPS cells by external causal forces) rather than something that they naturally bring about themselves. For example, the presence of tetraploidized helper cells is itself neither normal nor natural, so any process that requires them would not naturally occur during development or embryogenesis. Moreover, if one were to claim that tetraploid complementation was an innate capacity of iPS cells it is not clear on what grounds one could claim that the induction of pluripotency was not an innate capacity of somatic cells, since both processes require equally artificial conditions. Yet, it would be absurd to contend that the advent of iPS cell technology has rendered somatic cells analogous to embryos. It follows that iPS cells cannot reasonably be thought to be analogous to embryos and so this ethical objection to using human iPS cells is unlikely to stand.

A final point worth considering is that the use of human iPS cells may not placate opponents of human PS cell research who view the harvesting of ES cells from human embryos as immoral. This is because the creation and use of human iPS cell lines depends on the use of human ES cells (including the application of technologies developed using human ES cells and the use of ES cells to confirm pluripotency). As a result, even researchers who confine themselves to the use of human iPS cells would have to be regarded by hard line opponents as complicit in the immoral destruction of embryos, since their understanding and application of the cells they use is dependent on human ES cell research and development [8]. Insofar as one makes use of or relies on other research findings, one implicitly validates and condones the conduct of that research. Thus, strictly speaking, those who consider current human PS cell research immoral cannot condone research using human iPS cells since that would amount to condoning immoral acts.

\section{Impact of Human iPS on Exploitation of Women and Commodification of Human Life}

Research conducted using human iPS cells would not raise any concerns about the potential exploitation of women since there would be no need to obtain human ova. The only human cells required for iPS cell derivation are somatic cells, and since the harvest of somatic cells is as simple as taking a cheek swab it does not pose any significant burdens or risks that could be disproportionately borne by disadvantaged groups. Somatic cells can also be harvested in virtually unlimited quantities, in contrast to the small number of ova a woman can produce in any one cycle. Hence it is unlikely that demand will ever exceed supply, obviating the need for (potentially exploitative) financial incentives. Ensuring that somatic cells for iPS cell production are obtained in an ethical manner would thus simply require ensuring that donor consent is obtained.

Despite the ready supply and easy access to somatic cells reducing the risk of commodification of human iPS cells, it does not eliminate it entirely. The underlying problem is not the literal buying and selling of human parts, it is the erosion of respect for the inherent value and dignity of human life that results when people start to view the constituents of human life (including embryos, gametes, somatic cells and genes) in instrumental terms. Thus, any form of research that requires the use of human cells, including iPS cells, raises concerns about commodification, since by its nature such research would encourage people to think of those cells in terms of their value to that research. For the same reason, any research that leads to the patenting (or other forms of ownership) of human cell lines, including iPS cell lines, would also raise concerns about commodification.

\section{POTENTIAL NEW PROBLEMS CREATED BY THE USE OF HUMAN IPS CELLS}

In addition to considering the ethical problems with human ES cell research that are potentially resolved by iPS cell technology, it is also important to consider new ethical issues that this technology raises related to the genetic manipulation of human somatic cells. First, conventional methods using viral vectors to deliver copies of reprogramming factors would result in an increased potential for adverse outcomes. The use of viral vectors to insert these factors into somatic cells resulted in iPS cells that contained large numbers of viral vector integrations increasing the chance of unpredictable genetic defects [35]. Hence, the use of virally induced iPS cells in experimental PS cell therapies would expose human subjects to excessive risk, making the use of conventional iPS cell types unethical under the principle of beneficence. However, recent success in 
inducing somatic cells to assume a stable pluripotent state without the use of viral vectors, by inserting a single excisable transgene or by directly inserting reprogramming proteins, suggests that these safety concerns can be overcome $[36,37]$. Using virus-free factors that can be removed once induction is complete, or protein factors that do not integrate into the cellular DNA, to induce pluripotency would allow the production of human iPS cells that do not carry an increased risk (in comparison with human ES cells) due to viral integration.

Because iPS cells are the product of genetic manipulation, the possibility of their reproductive use via tetraploid complementation raises additional ethical concerns related to germline alteration. In the event that iPS cells are used for reproductive cloning, any genetic alterations carried by the cells might be carried into future generations and have unpredictable effects. However, the possibility of using virus-free excisable factors to derive iPS cells could reasonably be expected to alleviate concerns over germline alteration.

Finally, although not an ethical problem per say, the ongoing focus on how human iPS cells provide researchers with a more ethical source of human PS cells may actually undermine support for human PS cell research generally even as it increases support for human iPS cell research. This is because it is likely to make it more difficult for researchers to justify the use of human ES cells since in the eyes of governments and the general public there is now a more ethical alternative [6]. This may translate to reduced public funding of research using ES cells, despite there being an ongoing need for such research [38].

\section{CONCLUDING REMARKS}

To conclude, the use of human iPS cells is significantly less ethically problematic than the use of human ES cells, not least of which is that the production of iPS cells does not require any direct harm to embryos and thereby largely avoids the main source of controversy in the stem cell debate. However, human iPS cells are unlikely to end the stem cell debate since they are generated through knowledge based on human ES cells, which will continue to be needed for the foreseeable future as "gold standard" PS cells. Moreover, the use of iPS cells raises ethical concerns specific to somatic cell reprogramming, although in many instances we can reasonably expect current problems to be overcome in the proximate future. Thus, while the use of human iPS cells will do much to mitigate the stem cell debate, the controversy will most certainly survive.

\section{ACKNOWLEDGEMENTS}

This study was supported by O'Brien Institute. We thank Professor Charles Weijer, Dept. of Philosophy, University of Western Ontario for critical review of the manuscript.

\section{REFERENCES}

[1] Baker M. James Thomson: shifts from embryonic stem cells to induced pluripotency. Nature Reports Stem Cells [serial on the
Internet] 2008 Aug 14; [cited 2009 Sept 21]. Available from: http://www.nature.com/stemcells/2008/0808/080814/full/stemcells. 2008.118.html

[2] Hornyak T. Turning back the cellular clock. Sci Am 2008; 299: 112-5.

[3] Takahashi K, Yamanaka S. Induction of pluripotent stem cells from mouse embryonic and adult fibroblast cultures by defined factors. Cell 2006; 126(4): 663-76.

[4] Scott CT, Reijo Pera RA. The road to pluripotence: the research response to the embryonic stem cell debate. Hum Mol Genet 2008; 17: R3-9.

[5] Meyer JR. The significance of induced pluripotent stem cells for basic research and clinical therapy. J Med Ethics 2008; 34: 849-51.

[6] Holm S. Time to reconsider stem cell ethics-the importance of induced pluripotent cells. J Med Ethics 2008; 34(2): 63-4.

[7] Denker HW. Induced pluripotent stem cells: how to deal with the developmental potential. Reprod Biomed Online 2009; 19(1): 34-7.

[8] Brown MT. Moral complicity in induced pluripotent stem cell research. Kennedy Inst Ethic J 2009; 19: 1-22.

[9] Dept of Health and Human Services, NIH, and Office for Human Research Protections. Protection of Human Subjects. 45 Code of Federal Regulations 46, 2001.

[10] The Ramsey Colloquium. The inhuman use of human beings: a statement on embryo research by the Ramsey Colloquium. First Things 1995; 49: 17-21.

[11] Ad Hoc Group of Consultants to the Advisory Committee to the Director, NIH. Report of the human embryo research panel, 1, 1994.

[12] Wakayama T, Tabar V, Rodriguez I, Perry AC, Studer L, Mombaerts P. Differentiation of embryonic stem cell lines generated from adult somatic cells by nuclear transfer. Science 2001; 292: 740-3.

[13] Wang L, Duan E, Sung LY, Jeong BS, Yang X, Tian XC. Generation and characterization of pluripotent stem cells from cloned bovine embryos. Biol Reprod 2005; 73(1): 149-55.

[14] Brambrink T, Hochedlinger K, Bell G, Jaenisch R. ES cells derived from cloned and fertilized blastocysts are transcriptionally and functionally indistinguishable. Proc Natl Acad Sci USA 2006; 103(4): 933-8.

[15] Munsie MJ, Michalska AE, O'Brien CM, Trounson AO, Pera MF, Mountford PS. Isolation of pluripotent embryonic stem cells from reprogrammed adult mouse somatic cell nuclei. Curr Biol 2000; 10(16): 989-92.

[16] Wakayama S, Jakt ML, Suzuki M, et al. Equivalency of nuclear transfer-derived embryonic stem cells to those derived from fertilized mouse blastocysts. Stem Cells 2006; 24(9): 2023-33.

[17] French A, Adams C, Anderson L, Kitchen J, Hughes M, Wood S. Development of human cloned blastocysts following somatic cell nuclear transfer (SCNT) with adult fibroblasts. Stem Cells 2008; 26: 485-93.

[18] Cervera RP, Stojkovic M. Commentary: somatic cell nuclear transfer progress and promise. Stem Cells 2008; 26: 494-5.

[19] Elshtain JB. In: Nussbaum MC, Sunstein CR, Ed. Clones and clones: facts and fantasies about human cloning. New York: Norton 1998; 181-9.

[20] Wachbroit R. Genetic encores: the ethics of human cloning. Report from the Institute for Philosophy and Public Policy 1997; 17(4): 17.

[21] Hurlbut WB. Ethics and embryonic stem cell research: altered nuclear transfer as a way forward. BioDrugs 2007; 21(2): 79-83.

[22] Meissner A, Jaenisch R. Generation of nuclear transfer-derived pluripotent ES cells from cloned Cdx2-deficient blastocysts. Nature 2006; 439: 212-5.

[23] Ryan MA. In: Lauritzen P, Ed. Cloning and the future of human embryo research. New York: Oxford UP 2001; 50-66.

[24] Schwartz PH, Rae SB. An approach to the ethical donation of human embryos for harvest of stem cells. Reprod Biomed Online 2006; $12: 771-5$.

[25] Chung Y, Klimanskaya I, Becker S, et al. Embryonic and extraembryonic stem cell lines derived from single mouse blastomeres. Nature 2006; 439: 216-9.

[26] Klimanskaya I, Chung Y, Becker S, Lu SJ, Lanza R. Human embryonic stem cell lines derived from single blastomeres. Nature 2006; 444: 481-5.

[27] Chan AWS, Dominko T, Luetjens CM, et al. Clonal Propagation of primate offspring by embryo splitting. Science 2000; 287: 317-9. 
[28] Murray TH. In: The worth of the child. Berkeley: U California P 1996; 30-40.

[29] Zhang X, De Los Angeles A, Zhang J. The art of human induced pluripotent stem cells: the past, the present and the future. Open Stem Cell J 2010; 2: 2-7.

[30] $\mathrm{Ng} \mathrm{V}, \mathrm{Oh} \mathrm{S}$, Choo Andre. iPS and ES cells; do both roads lead to Rome: Open Stem Cell J 2010; 2: 8-17.

[31] Wernig M, Meissner A, Foreman R, et al. In-vitro reprogramming of fibroblasts into a pluripotent ES-cell-like state. Nature 2007; 448: 318-24.

[32] Kang L, Wang J, Zhang Y, Kou Z, Gao S. iPS cells can support full-term development of tetraploid blastocyst-complemented embryos. Cell Stem Cell 2009; 5(2): 135-8.

[33] Zhao XY, Li W, Lv Z, et al. iPS cells produce viable mice through tetraploid complementation. Nature 2009; 461: 86-90.
[34] Nakanishi M, Kurisaki A, Hayashi Y, et al. Directed induction of anterior and posterior primitive streak by Wnt from embryonic stem cells cultured in a chemically defined serum-free medium. FASEB J 2009; 23: 114-22.

[35] Soldner F, Hockemeyer D, Beard C, et al. Parkinson's disease patient-derived induced pluripotent stem cells free of viral reprogramming factors. Cell 2009; 136: 964-77.

[36] Kaji K, Norrby K, Paca A, Mileikovsky M, Mohseni P, Woltjen K. Virus-free induction of pluripotency and subsequent excision of reprogramming factors. Nature 2009; 458: 771-6.

[37] Dohoon K, Chun-Hyung K, Jung-Il M, et al. Generation of human induced pluripotent stem cells by direct delivery of reprogramming proteins. Cell Stem Cell 2009; 4: 472-6.

[38] Gottweis H, Minger S. iPS cells and the politics of promise. Nature Biotechnol 2008; 26: 271-2.

Received: November 11, 2009

Revised: March 10, 2010

Accepted: March 11, 2010

(C) Watt and Kobayashi; Licensee Bentham Open.

This is an open access article licensed under the terms of the Creative Commons Attribution Non-Commercial License (http://creativecommons.org/licenses/by$\mathrm{nc} / 3.0 /$ ), which permits unrestricted, non-commercial use, distribution and reproduction in any medium, provided the work is properly cited. 